\title{
Estratégia saúde da família e análise da realidade social: subsídios para políticas de promoção da saúde e educação permanente
}

\author{
Family health strategy and analysis of the social reality: input for \\ policies for promotion of health and permanent education
}

Charles Dalcanale Tesser ${ }^{1}$ Adir Valdemar Garcia ${ }^{2}$ Carine Vendruscolo ${ }^{3}$ Cleonete Elena Argenta ${ }^{2}$
${ }^{1}$ Departamento de Saúde Pública, Universidade Federal de Santa Catarina. Rua Roberto Sampaio Gonzaga s/n, Trindade. 88040-900 Florianópolis SC.

charlestesser@ccs.ufsc.br

${ }^{2}$ Escola de Saúde Pública de

Santa Catarina, Secretaria de Estado de Saúde

${ }^{3}$ Universidade Comunitária

Regional de Chapecó
Abstract The results of a qualitative study, carried out between 2007 and 2009 in three cities of Greater Florianópolis into the reality of the family health teams are presented. The scope was to investigate if the analysis of social and health reality was conducted and to what extent it contributed to the inclusion of local actions aiming at health promotion $(H P)$ and permanent education (PE). The results showed that HP and PE, respectively, were being confused with disease prevention and ongoing education and were seldom present in the work of the professionals. Also, they revealed an educational and preventive "spirit," with a didactic approach based on unidirectional transmission of content. Social and health reality were not analyzed in depth and in most cases did not create effective actions to promote health, nor were there processes of permanent education. The practices of recording data by the Health Community Agents were merely compliance with a bureaucratic necessity, although healthcare and prevention require actions of an educational nature. The conclusion reached is that permanent education does not exist in these teams and its introduction can contribute to broaden understanding of health promotion practices.

Key words Health promotion, Permanent education, Health policies, Primary care
Resumo $O$ artigo discute a análise da realidade elaborada por equipes de saúde da família, sintetizando resultados de estudo com abordagem qualitativa realizado em três municípios da Grande Florianópolis. O objetivo foi investigar se e de que maneira a análise da realidade social e de saúde era feita e como contribuía para a proposição de ações de promoção da saúde e de educação permanente. Observou-se que a promoção da saúde era confundida na maioria das vezes com prevenção de doenças e a educação permanente com educação continuada, estando ambas pouco presentes no trabalho dos profissionais. Destacou-se nas equipes um "espirito" educativo e preventivo, com visão predominantemente da educação como transmissão unidirecional de conhecimento. A realidade social e de saúde era pouco analisada, não resultando, na maioria dos casos, em proposições de ações de promoção da saúde, nem havia processos de educação permanente. As práticas de registro de dados pelos Agentes Comunitários de Saúde tinham caráter de cumprimento de obrigações burocráticas, embora as necessidades de cuidado e de prevenção suscitassem ações com caráter educativo. Concluiu-se que a educação permanente inexiste nessas equipes e que sua introdução pode contribuir para ampliar o entendimento e a prática da promoção da saúde.

Palavras-chave Promoção da saúde, Educação permanente, Políticas de saúde, Atenção primária 


\section{Introdução}

Há boas evidências sobre o papel central da atenção primária à saúde (APS) na organização de sistemas de saúde públicos e universais que provenham cuidado integral aos seus cidadãos ${ }^{1}$, e a Estratégia Saúde da Família (ESF) é apontada como eixo estruturante da APS no Sistema Único de Saúde (SUS). A atuação das equipes da ESF deve envolver ações e subsidiar políticas de promoção da saúde, ao menos no âmbito local e municipal, onde as análises da realidade social e de saúde são processos de grande valia, uma vez que se espera delas também atuação no território, enfoque familiar e comunitário e abordagem de problemas psicossociais e sociosanitários em parcerias com os usuários e outros setores governamentais e não governamentais. Esse conjunto está diretamente envolvido em pelo menos oito das treze atribuições comuns a todos os profissionais das equipes de saúde da família listadas na Política Nacional de Atenção Básica², editada em 2006, hoje vigente. Doutra parte, a educação permanente (EP) oferece elementos valiosos ao prover uma visão geral filosófica-política e técnicapedagógica para o processo de formação e aperfeiçoamento constante dos profissionais da saúde em relação aos desafios de seu trabalho cotidiano. É fundamentada na concepção de educação como transformação e aprendizagem significativa, centrada no exercício cotidiano do trabalho e na valorização deste como fonte de conhecimento, na valorização da articulação da atenção à saúde com a gestão e o controle social e no reconhecimento de que as práticas são definidas por múltiplos fatores. Volta-se à multiprofissionalidade $\mathrm{e}$ à interdisciplinaridade, com estratégias de ensino contextualizadas e participativas, e orienta-se para a transformação das práticas ${ }^{3-5}$. Essas características diferenciam-na da educação continuada (EC), pautada na concepção de educação como transmissão de conhecimento e na valorização da ciência como fonte do conhecimento, pontual, fragmentada e construída de forma não articulada à gestão e ao controle social, com enfoque nas categorias profissionais e no conhecimento técnico-científico de cada área ${ }^{3}$.

A educação permanente e os desafios impostos pelas várias missões da ESF convergem com a construção de valores, métodos e práticas democratizantes de gestão do trabalho no SUS, visando sua qualificação e enriquecimento. Implicam em esforço para o fortalecimento da capacidade de cogestão dos processos de trabalho, de análise e de intervenção em realidades individuais e sociosanitárias e de capacidade de cuidado, a partir de arranjos institucionais facilitadores desses processos ${ }^{6}$. A política de educação permanente deve contribuir para aprimorar o processo de conhecimento e análise da realidade social, bem como aumentar a resolubilidade, a longitudinalidade, a humanização, a coordenação do cuidado e a competência pedagógica e cultural para o processo progressivo de "empowerment comunitário"” de que fala a promoção da saúde.

O impacto das discussões sobre a promoção da saúde (PS) foi grande ${ }^{8}$. No Brasil, esse movimento foi contemporâneo da constituição do SUS e influenciou a ESF e a Saúde Coletiva, com a qual tem muitas convergências ${ }^{5}$. Várias iniciativas e experiências institucionais foram realizadas ${ }^{9,10}$, bem como foram suscitadas discussões e identificadas diferentes vertentes nesse campo ${ }^{11,12}$. A promoção da saúde é aqui assumida numa vertente crítica que enfatiza tanto os aspectos de determinação social do processo saúde-doençaatenção (os quais deságuam em certa priorização de ações voltadas para esses determinantes gerais) quanto os aspectos de educação e promoção de saúde ligados à cultura e aos comportamentos individuais, estes com ênfase na ressignificação compartilhada da vida e de seus sentidos e projetos, evitando a tendência medicalizante e controladora da simples prescrição de comportamentos ditos saudáveis, de viés, muitas vezes, autoritário, culpabilizante ${ }^{13}$, higiomaníaco ${ }^{14,15}$ e pouco efetivo.

Quanto ao significado do termo "empowerment", seguindo Carvalho ${ }^{7}$, adotou-se a ideia de "empowerment" comunitário, que toma por base uma noção de poder como recurso, material e imaterial, distribuído desigualmente na sociedade, no qual convivem dimensões produtivas, potencialmente criativas e instituintes, com elementos de conservação do status quo. Neste enfoque supõe-se alto teor de "empowerment" psicológico individual, mas, além disso, fatores associados a distintas esferas da vida microssocial e macrossocial se fazem presentes e enriquecem a perspectiva político-filosófica de forma crítica e coerente com valores de solidariedade, justiça, liberdade, fraternidade, redistribuição de poderes e riquezas, excessivamente concentrados. $\mathrm{O}$ pressuposto assumido é que tal significado necessita ser desenvolvido, ampliado e fortalecido na dimensão pedagógica e política das práticas em saúde na ESF.

A inter-relação entre as propostas da educação permanente e da promoção da saúde com a ESF é uma proposição bastante profícua e cabe 
investigar se nas práticas das equipes da ESF ela vem acontecendo, e como. Este artigo apresenta resultados de uma pesquisa sobre se e de que maneira a análise da realidade social e de saúde elaborada por equipes da ESF está sendo utilizada para a geração de ações locais de promoção da saúde e de educação permanente.

\section{Métodos}

Trata-se de um estudo descritivo desenvolvido entre 2007 e 2009, na Grande Florianópolis (SC), com uma aproximação metodológica qualitativa que privilegiou a descrição (o que e como) e a compreensão dos significados das práticas e ideias investigadas: como se dá a análise da realidade sociossanitária nas equipes de saúde da família e como se articulam (ou não) com ações de promoção da saúde e educação permanente. A coleta de dados foi feita junto a profissionais da ESF por meio de duas técnicas com função complementar: entrevistas, para perscrutar com maior profundidade e detalhe as questões investigadas, e questionários enviados a um número maior de profissionais, como técnica complementar visando ampliar o espectro de equipes abordadas (evitando a restrição dos dados a práticas idiossincráticas ou muito particulares, dada a conhecida heterogeneidade das equipes da ESF).

As entrevistas com roteiros semiestruturados foram realizadas com profissionais de três municípios da Grande Florianópolis (de grande, médio e pequeno porte) e com gestores municipais dessa Estratégia, nos locais de trabalho, após agendamento. Foram gravadas e transcritas. Incluíram duas equipes de saúde da família dos municípios menores e três do maior. Os critérios de seleção das equipes foram, primeiramente, estarem inseridas em distintas realidades sociais e terem profissionais atuando há mais tempo; em segundo plano, serem acessíveis. Os profissionais entrevistados foram: médico, enfermeiro, cirurgião dentista e um agente comunitário de saúde (ACS) de cada equipe, além do gestor, totalizando 31 sujeitos.

Foram distribuídos 112 questionários autoaplicáveis, com questões abertas com o mesmo teor das entrevistas, para serem respondidos por profissionais de outras 28 equipes escolhidas com mesmos critérios, proporcionalmente, ao volume de equipes dos municípios. A distribuição foi feita pelos gestores municipais, que também os recolheram. Retornaram 41 (36,6 \%) questionários respondidos, sendo 11 de um município (02 cirurgiões dentistas, 02 médicos, 03 enfermeiros 04 ACS), 17 de outro município (03 cirurgiões dentistas, 03 médicos, 03 enfermeiros, 05 ACS, 03 técnicos de enfermagem), e 13 do terceiro (01 cirurgião dentista, 02 médicos, 03 enfermeiros, 07 ACS). Assim, o conjunto total dos sujeitos investigados foi de 69 profissionais que atuavam em equipes da ESF (13 cirurgiões dentistas, 14 médicos, 16 enfermeiros, 23 ACS e 03 técnicos de enfermagem - estes últimos responderam apenas ao questionário), além dos gestores, o que totalizou 72 participantes.

O material coletado foi pré-analisado (conforme $\operatorname{Bardin}^{16}$ ) por todos os pesquisadores. Inicialmente foi separado por município e por instrumento (entrevistas e questionários) e após, analisado globalmente. A unidade de análise central foi composta pelas práticas de análise da realidade social das equipes em sua específica articulação com as ideias e ações de promoção da saúde e educação permanente encontradas. Foi realizada leitura e releitura do material a fim de buscar os significados atribuídos pelos sujeitos às noções e aos conceitos em foco, bem como apreender como se dão as práticas a eles associadas e sua inter-relação. Em seguida, foram detectadas as "unidades de significado" indicando temas recorrentes destacáveis das percepções e práticas relatadas pelos sujeitos, os quais foram reagrupados em categorias delineadoras da estrutura mais ampla do fenômeno ${ }^{17}$. Por fim, os resultados foram discutidos à luz dos pressupostos e referenciais conceituais, extremamente sintetizados na introdução.

No texto, as falas serão identificadas por uma sigla contendo o número do município e da equipe, bem como a letra relativa ao profissional. Por exemplo, M1E1D significa que a citação veio do dentista da equipe 1 do município 1 . Os questionários foram identificados acrescentando-se a letra "Q" e uma numeração do profissional (M1QM1 = questionário do médico 1 do município 1).

A pesquisa cumpriu as determinações da Resolução 196/96 do Conselho Nacional de Saúde, tendo sido aprovada pelo Comitê de Ética em Pesquisa da UFSC.

\section{Resultados e discussão}

O perfil dos participantes da pesquisa (exceto gestores) encontra-se na Tabela 1 e revela que o grupo incluiu, como almejado, profissionais de várias idades, formações, origens acadêmicas e 
Tabela 1. Perfil dos participantes da pesquisa

\begin{tabular}{|c|c|c|c|c|c|c|c|c|c|}
\hline & \multicolumn{4}{|c|}{$\begin{array}{l}\text { Profissionais de } \\
\text { nível superior }\end{array}$} & \multicolumn{4}{|c|}{$\begin{array}{l}\text { Agentes Comunitários de Saúde } \\
\text { (+3 técnicos de enferm. de M2 ) }\end{array}$} & \multirow[b]{2}{*}{ Total } \\
\hline & $\mathrm{M1}^{*}$ & M2 & M3 & Sub total & M 1 & M2 & M3 & Sub total & \\
\hline \multicolumn{10}{|l|}{ Faixa etária (anos) } \\
\hline $21-25$ & 02 & 04 & 04 & $10(23 \%)$ & - & 01 & 03 & $04(15 \%)$ & $14(20 \%)$ \\
\hline $26-30$ & 05 & 06 & 04 & $15(35 \%)$ & - & 02 & 03 & $05(19 \%)$ & $20(29 \%)$ \\
\hline $31-35$ & 01 & 01 & 01 & $03(07 \%)$ & 01 & 01 & - & $02(08 \%)$ & $05(07 \%)$ \\
\hline $36-40$ & 03 & - & 01 & $04(09 \%)$ & 03 & - & 01 & $04(15 \%)$ & $08(12 \%)$ \\
\hline $41-45$ & 02 & 01 & - & $03(07 \%)$ & 02 & 03 & 02 & $07(27 \%)$ & $10(14 \%)$ \\
\hline $46-50$ & 01 & - & 01 & $02(05 \%)$ & - & 03 & - & $03(12 \%)$ & $05(07 \%)$ \\
\hline $51-55$ & 01 & - & 01 & $02(05 \%)$ & 01 & - & - & $01(04 \%)$ & $03(04 \%)$ \\
\hline$>55$ & 01 & 02 & - & $03(07 \%)$ & - & - & - & - & $03(04 \%)$ \\
\hline Sem informação & - & 01 & - & $01(02 \%)$ & - & - & - & - & $02(03 \%)$ \\
\hline \multicolumn{10}{|l|}{ Sexo } \\
\hline Masculino & 10 & 05 & 05 & $20(46,5 \%)$ & - & - & - & - & $20(29 \%)$ \\
\hline Feminino & 06 & 10 & 07 & $23(53,5 \%)$ & 07 & 10 & 09 & $26(100 \%)$ & $49(71 \%)$ \\
\hline \multicolumn{10}{|c|}{ Tempo de formado (em anos) } \\
\hline$<1$ & - & 01 & - & $01(02 \%)$ & - & - & - & - & $01(01 \%)$ \\
\hline $1-2$ & 03 & 05 & 05 & $13(30 \%)$ & 01 & 03 & 01 & $05(19 \%)$ & $10(15 \%)$ \\
\hline $3-4$ & 03 & 04 & 04 & $11(26 \%)$ & 01 & 02 & 02 & $05(19 \%)$ & $16(23 \%)$ \\
\hline $5-6$ & 01 & 02 & 01 & $04(09 \%)$ & 01 & 03 & 02 & $06(23 \%)$ & $10(15 \%)$ \\
\hline $7-10$ & 02 & - & - & $02(05 \%)$ & - & 02 & 01 & $03(12 \%)$ & $05(07 \%)$ \\
\hline $10-20$ & 04 & 01 & 01 & $06(14 \%)$ & - & - & - & - & $06(09 \%)$ \\
\hline$>20$ & 02 & 02 & 01 & $05(11 \%)$ & - & - & - & - & $05(07 \%)$ \\
\hline Sem informação & - & - & - & - & 04 & - & 03 & $07(27 \%)$ & $07(10 \%)$ \\
\hline \multicolumn{10}{|l|}{ Tipo de escola } \\
\hline Pública & 11 & 05 & 04 & $20(47 \%)$ & 01 & 02 & 02 & $05(19 \%)$ & $25(36 \%)$ \\
\hline Privada & 05 & 03 & 04 & $12(28 \%)$ & 02 & - & - & $02(08 \%)$ & $14(20 \%)$ \\
\hline Sem informação & - & 07 & 04 & $11(25 \%)$ & 04 & 08 & 07 & $19(73 \%)$ & $30(44 \%)$ \\
\hline \multicolumn{10}{|c|}{$\begin{array}{l}\text { Tempo de trabalho na ESF } \\
\text { (em anos) }\end{array}$} \\
\hline$<1$ & 02 & 05 & - & $07(16 \%)$ & - & - & - & - & $07(10 \%)$ \\
\hline $1-2$ & 07 & 05 & 08 & $20(47 \%)$ & 01 & 01 & 08 & $10(39 \%)$ & $30(43 \%)$ \\
\hline $3-4$ & 03 & 04 & 03 & $10(23 \%)$ & - & 04 & 01 & $05(19 \%)$ & $15(22 \%)$ \\
\hline $5-6$ & 01 & 01 & 01 & $03(07 \%)$ & 02 & 03 & - & $05(19 \%)$ & $08(12 \%)$ \\
\hline $7-8$ & 03 & - & - & $03(07 \%)$ & 04 & 02 & - & $06(23 \%)$ & $09(13 \%)$ \\
\hline \multicolumn{10}{|c|}{$\begin{array}{l}\text { Tempo de trabalho na equipe } \\
\text { de SF (anos) }\end{array}$} \\
\hline$<1$ & 06 & 10 & 06 & $22(51 \%)$ & - & 01 & - & $01(04 \%)$ & $23(33 \%)$ \\
\hline $1-2$ & 05 & 04 & 05 & $14(33 \%)$ & 02 & 02 & 08 & $12(46 \%)$ & $26(38 \%)$ \\
\hline $3-4$ & 04 & - & 01 & $05(12 \%)$ & 01 & 03 & 01 & $05(19 \%)$ & $10(15 \%)$ \\
\hline $5-6$ & - & 01 & - & $01(02 \%)$ & 01 & 03 & - & $04(15 \%)$ & $05(07 \%)$ \\
\hline $7-10$ & 01 & - & - & $01(02 \%)$ & 02 & 01 & - & $03(12 \%)$ & $04(06 \%)$ \\
\hline Sem informação & - & - & - & - & 01 & - & - & $01(04 \%)$ & $01(01 \%)$ \\
\hline Totais & 16 & 15 & 12 & $43(100 \%)$ & 07 & 10 & 09 & $26(100 \%)$ & $69(100 \%)$ \\
\hline
\end{tabular}

${ }^{*} \mathrm{Mn}=$ Município $\mathrm{n}$

tempo de exercício profissional na área da saúde e, especificamente, na ESF. Essa variedade era esperada e corroborou o saber comum de que a rotatividade de profissionais na ESF é grande.

Na pré-análise do material notou-se que não houve diferenças significativas nos resultados entre os municípios quanto aos conteúdos e prá- ticas referidos pelos entrevistados. Tampouco se constatou diferenças relevantes entre as categorias profissionais, diferentemente do que se poderia esperar. O mesmo ocorreu quando foram comparados os dados das entrevistas com os dos questionários. Embora haja exceções localizadas e algumas variações, o primeiro resultado im- 
portante foi uma considerável convergência de entendimentos e de práticas sobre promoção da saúde, educação permanente, descrições e análises da realidade social, tipos de ações correlatas e fluxos de informação e demandas, que permite uma íntima articulação entre os mesmos.

Dado o grande volume de dados coletados e de análises possíveis, optou-se por apresentar os resultados considerados mais importantes frente aos objetivos da pesquisa. A Figura 1 ilustra, na sua parte superior, o panorama geral dos resultados, através de uma listagem das principais categorias identificadas, e na sua parte inferior o esquema que sintetiza os nexos e coerências entre alguns dos achados que reforçam os resultados no seu conjunto e delineiam práticas que pare-

\begin{tabular}{|c|c|}
\hline \multicolumn{2}{|c|}{ PANORAMA GERAL DOS RESULTADOS } \\
\hline $\begin{array}{l}1 \text { - Entendimentos sobre promoção da saúde (PS): } \\
\text { A - = Prevenção de doenças } \\
\text { B - Melhorar qualidade de vida } \\
\text { C - Empowerment, controle social, ação sobre } \\
\text { determinantes sociais }\end{array}$ & $\begin{array}{l}2 \text { - Entendimentos sobre educação permanente (EP): } \\
\text { C - Treinamento em serviço, capacitação para o } \\
\text { trabalho, atualização clínica } \\
\text { D - Discussão, estudo e aprendizado significativo } \\
\text { a partir da prática }\end{array}$ \\
\hline $\begin{array}{l}3 \text { - Práticas de PS: } \\
\text { E - Orientação familiar e individual } \\
\text { F - Grupos educativos e palestras } \\
\text { G - Controle social, ações políticas e sociais }\end{array}$ & $\begin{array}{l}4 \text { - Práticas de EP: } \\
\text { H - Cursos e treinamentos, atualizações } \\
\text { I - Discussões, estudos e aprendizados relevantes } \\
\text { para prática (ausente na ESF) }\end{array}$ \\
\hline \multicolumn{2}{|c|}{$\begin{array}{l}5 \text { - Obtenção e registro de dados e análise da realidade das áreas: } \\
\text { J - Registro de dados (cadastro das famílias (CADFamília) e SIAB (obrigatório). } \\
\text { K - Discussões entre ACSs e enfermeiro de casos clínicos e problemas demandantes. } \\
\text { L - Discussões entre ACSs e enfermeiro de registros e SIAB. } \\
\text { M - Discussões em reuniões da equipes de SF de casos clínicos e problemas demandantes. } \\
\text { N - Discussões em reuniões das equipes de SF de registros e SIAB. }\end{array}$} \\
\hline \multicolumn{2}{|c|}{$\begin{array}{l}6 \text { - Fluxos de dados, demandas e iniciativas de ações de PS e EP } \\
\text { O - Atividades educativas e de prevenção individuais e grupais (grupos, palestras em outras } \\
\text { instituições, visitas domiciliares, etc.), com caráter de orientação individual, familiar e grupal, de } \\
\text { rotina, periódicas ou episódicas, a partir de demandas sentidas. } \\
\text { P - Demandas de apoio interdisciplinar de outros serviços (zoonoses, vigilância, nível secundário - } \\
\text { DST, nutrição, fonoaudiologia, etc.) a partir de demandas específicas sentidas no dia-a-dia. } \\
\text { Q - Encaminhamento de dados (SIAB) para Secretaria Municipal de Saúde, por obrigação } \\
\text { burocrática. } \\
\text { R - Análise e avaliação a partir do SIAB e dos marcadores eleitos pelo município. }\end{array}$} \\
\hline
\end{tabular}

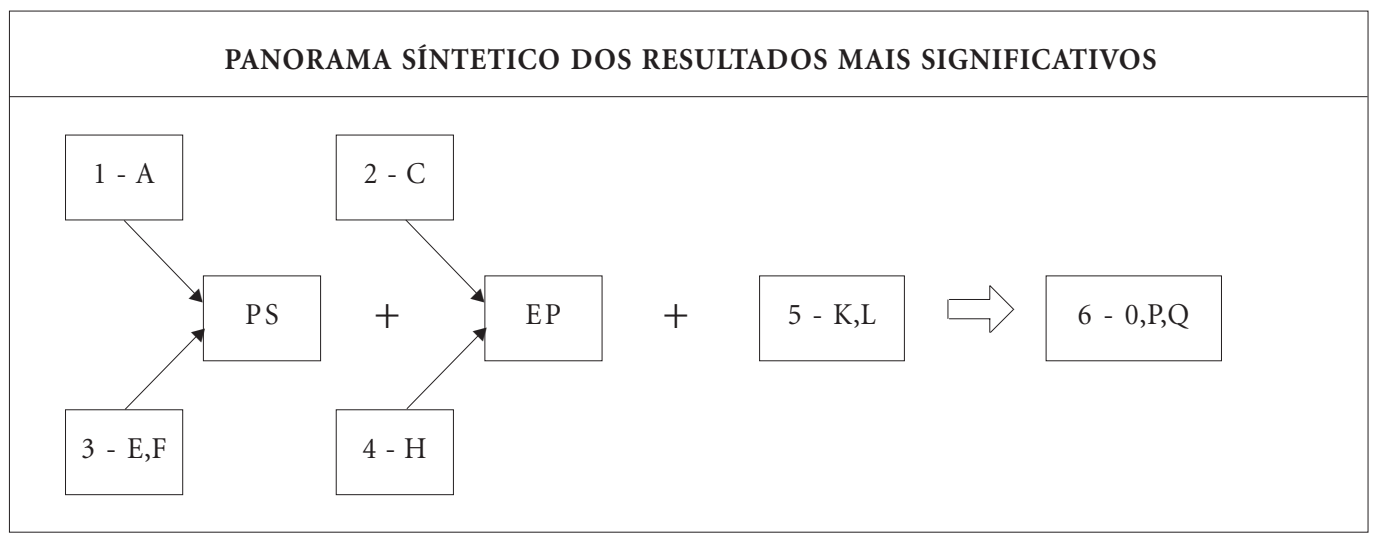

Figura 1. Esquema de apresentação dos resultados 
cem hegemônicas. Assim, uma compreensão de promoção da saúde mais presente (1A: promoção = prevenção, na Figura 1) associou-se às práticas respectivas mais comuns relatadas (3E, F: orientação educativa individual ou grupal), e essas entraram em harmonia com um entendimento de educação permanente $(2 \mathrm{C}: \mathrm{EP}=\mathrm{EC})$ e sua prática ( $4 \mathrm{H}$ : treinamentos e cursos). Esse conjunto somou-se com as principais formas de obtenção, registro e análise de dados das realidades sociais das equipes $(5 \mathrm{~K}, \mathrm{~L}$ : discussões de casos e problemas e do Sistema de Informação da Atenção Básica - SIAB pelas ACS com a enfermeira), conformando fluxos de geração de ações e demandas de ações de promoção de saúde e educação permanente, ou do que os entrevistados concebiam como tal (6O, P: atividades educativas individuais e grupais).

\section{A compreensão sobre promoção da saúde e educação permanente}

A grande maioria dos profissionais entendia promoção de saúde como prevenção de doenças, o que é repetitivo tanto nas respostas das entrevistas quanto dos questionários: "Promoção da saúde é estar fazendo campanha, as campanhas pra prevenção, é estar chamando as mulheres pra fazer o preventivo" (M1E3E); "é orientar o paciente a se prevenir" (M3E2ACS).

As concepções sobre promoção de saúde apresentaram-se, hegemonicamente, como se o modelo da história natural da doença de Leavell e Clark $^{18}$ vigorasse como referência teórica atual, havendo uma relativa ausência de menção aos questionamentos a seu respeito, bem como aos conhecimentos e discussões sobre o processo saúde-doença, seus determinantes e a promoção da saúde numa visão pós-Carta de Otawa. Houve menções genéricas associando promoção com melhora da qualidade de vida, mas as práticas e os exemplos de ações de promoção mencionados tendiam fortemente para a prevenção de doenças e de riscos específicos.

Notou-se pouca menção a abordagens coletivas e "empoderadoras" que apontassem para a participação social e política ou que vislumbrassem objetivos ou direções de "empowerment" coletivo, apenas apontados por alguns entrevistados, como por exemplo: "[promoção] envolve não só o setor saúde. [...] uma ciclovia, uma passarela para fazer caminhada, estruturar as praças plantando árvores, [...] estrutura de lazer, ter acesso aos serviços todos, públicos, ter uma qualidade de vida boa que inclui habitação, renda, educação que foge a nós da saúde administrar, mas eu acho que nós temos uma responsabilidade de fomentar a comunidade, o cidadão a buscar isso" (M2E1E).

Coerente com a visão preventivista, e talvez mesmo hegemônica, em termos de representações sociais medicalizadas sobre o processo saúde-doença ${ }^{14}$, a maioria dos informantes reduziu os significados da promoção da saúde e a traduziu em termos de práticas assistenciais como orientações individuais e familiares que se realizam nos serviços de atenção primária à saúde (APS), nas visitas domiciliares, nos grupos, etc. A promoção, neste caso, é subsumida completamente pela educação em saúde, esta vista numa perspectiva individual ou familiar mais ou menos contextualizadora, mas claramente centrada na transmissão unidirecional de conteúdos: os profissionais teriam como função veicular as informações corretas e atualizadas aos usuários e comunidades, para que estes possam se comportar adequadamente e prevenir as doenças, com o que estariam promovendo sua saúde: "A promoção, [...] é levando informação [...], conversando com as pessoas, ensinando elas" (M1E3ACS); "Levando conhecimento." (M1E3D). Com efeito, isso converge com o que se ensina em escolas formadoras de profissionais e se pratica na APS brasileira em outros locais ${ }^{2,19,20}$.

Esses achados revelaram um ideário preventivista centrado em ações de educação em saúde de cunho individual (e grupal) de tendência bancária, conforme Freire ${ }^{21,22}$, em que a transmissão verticalizada de conhecimentos parece dominar a cena. Tal perspectiva, antiga, persiste e está relacionada com a cultura institucional e com a formação profissional. Trabalhos anteriores, realizados com equipes de saúde da família em Florianópolis, demonstraram que a ESF contribuiu para avanços na prevenção e na consciência sanitária, bem como avançou na realização de visitas domiciliares, além de uma maior disponibilidade de consultas médicas. Embora alguns destes aspectos sugiram a forte predominância do modelo biomédico tradicional, por outro lado, há indícios apontando para a viabilidade de práticas mais abrangentes, demonstrando potencialidades da Estratégia no sentido de reorientar o modelo tradicional na rede pública de saúde lo$\mathrm{cal}^{23,24}$. Porém, tais avanços parecem não resultar em uma mudança significativa quanto a promoção da saúde.

De forma coerente com a visão preventivista e individualista da promoção da saúde apresentada, os profissionais que conheciam a expres- 
são educação permanente (EP) - vários a desconheciam, principalmente dentre os ACS - a identificaram (com pequena variação e duas exceções), com a educação continuada (EC), na forma de cursos de atualização e capacitação: "educação permanente, eu acho que são cursos de capacitação... educação continuada" (M1E2D); "Reciclagem pessoal no sentido de estar sempre melhorando, se atualizando, cada um na sua área” (M2E2D).

Ressalta-se o desconhecimento pela grande maioria dos profissionais investigados sobre as propostas de educação permanente produzidas nos últimos anos na Saúde Coletiva e assumidas pelo SUS. Também se notou a ausência de práticas de EP nestes municípios, o que converge com Pessanha e Cunha ${ }^{25}$ quando analisam a aprendizagem-trabalho dos profissionais da ESF e a pouca utilização da EP pelos gestores. Salvo poucas exceções, nos sujeitos investigados destes três municípios e, possivelmente, de muitos outros locais do Brasil a educação permanente é vista como outro nome da educação continuada, cujo objetivo seria atualizar conteúdos nas mentes dos profissionais, para qualificar sua prática e tornálos fiéis transmissores dos conhecimentos aos usuários. Deve-se ressaltar a coerência com que se harmonizam as visões acima de educação permanente e promoção da saúde: a informação atualizada seria necessária para possibilitar a promoção da saúde entendida como educação e orientação individual e familiar.

Outro aspecto que merece destaque é a pluralidade de ambientes e formas em que se concretiza a promoção da saúde, espaços institucionais, sociais e domésticos, escolas, centros comunitários e serviços de saúde: "grupos de idosos, hipertensos, gestantes, planejamento familiar, etc. Visita domiciliar. Estratégias de educação em saúde inseridas na comunidade/escolas" (M1QE1). Pouquíssimos profissionais com uma visão ampliada da promoção destacaram a intersetorialidade e acrescentaram outros espaços ou dimensões para a mesma (mídia, políticas públicas, ações sociais e políticas, Conselhos de Saúde, lazer) e um único entrevistado enfatizou este aspecto: “o posto de saúde é um dos lugares onde menos acontece promoção da saúde" (M1E1M).

O olhar crítico para com essa visão restrita da promoção, que a identifica com prevenção de doenças e a restringe à educação em saúde, e para com a identificação da EP com a EC, não visa desqualificar ou subvalorizar a educação em saúde ou as informações científicas. Evidente que o desenvolvimento de habilidades pessoais é um dos cinco campos clássicos de ação da promoção da saúde, em que a educação é importante; no entanto ele é tão somente um deles ${ }^{8}$. Porém mesmo considerando a educação, as práticas centradas na transmissão unidirecional de informações são por demais pouco efetivas, pouco educativas e insuficientes quanto ao complexo processo saúde-doença-atenção, tanto em termos culturais ou sócio-políticos como na abordagem individual ${ }^{26}$.

Esses achados fazem pensar que há um forte habitus, conforme Bourdieu ${ }^{27}$, preventivista e de educação unidirecional, dominando as equipes investigadas e, talvez, a APS brasileira, possivelmente herança cultural atávica dos primeiros centros de saúde norte-americanos e brasileiros do início do século $\mathrm{XX}^{28,29}$, que resiste aos novos tempos, ideias e práticas, associada a um preventivismo ainda hoje forte. Deve-se lembrar que a quase ausência de uma visão que valoriza as questões sociais, políticas e culturais entre os profissionais de saúde é um grave problema, já que a participação, a mobilização social e política e o "empowerment" coletivo são necessários para a sustentabilidade e o aprofundamento da construção da ESF e do SUS.

\section{Descrição e análise da realidade social}

Os profissionais investigados foram convidados a descrever a realidade social e de saúde de suas áreas, inclusive do ponto de vista da organização e participação política. A questão foi estrategicamente colocada, pois uma descrição da realidade social supõe algum grau de análise e apreensão, individual ou coletiva, organizada ou não, dessa realidade. Houve aqui também uma considerável homogeneidade de respostas, que consistiu em avaliações sobre o que se poderia chamar "grau de pobreza" ou "nível econômico" local. As descrições variaram, pois as realidades eram distintas, mas o teor era o mesmo: "classe média", "média alta", "média baixa", "baixa", "precária", "muito carente" e "pobreza muito grande". Notou-se certa superficialidade nas descrições e pouca menção à história local, às origens étnicas ou geográficas (migratórias) das pessoas, a características culturais e ocupacionais.

Nas equipes em que a situação social era considerada "carente" foi relatada dificuldade para o trabalho de promoção (restrita, como já dito, à orientação) com as famílias mais pobres e com menor instrução: "O pessoal lá da minha área [...] A maioria tem uma penca de filhos, um monte de cachorro e, [...] não têm casa própria, 
[...] situação bem precária, mesmo! A gente vai lá, tenta ajudar, e assim, quanto mais a gente pede, mais eles não se cuidam, mais têm filhos, a situação vai ficando pior [...]." (M3E1ACS).

Quanto à organização social e política das comunidades, houve, novamente, certa homogeneidade importante por trás da aparente heterogeneidade nas respostas: o conjunto dos entrevistados, com duas exceções, não considerou o envolvimento ou a contribuição para essa organização (fomento ao "empowerment" comunitário) como objeto de seu trabalho e não se envolveu ou à sua equipe nessa descrição. Os profissionais falaram do grau de atuação, participação e organização comunitária, referindo-se a centros comunitários e seus líderes, conselhos locais de saúde, usuários ou grupos específicos de forma quase nada relacionada ao trabalho das equipes. Referindo-se sempre a ela (a comunidade) ou a eles (os usuários, seus líderes ou grupos), não aludiram a alguma atuação sua nessa seara, em organização de Conselhos Locais de Saúde ou fomento à organização comunitária: "Eles não têm um grupo formado, não têm um conselho de bairro, entendeu, não tem aqui, eles só têm um grupinho de idosos, que são poucos que vão..." (M3E1E); "Eles são participantes, a gente vê que tem a troca com o posto, eles estão sempre procurando fazer [...]. Eles são, são atuantes sim". (M1E3E); "Ausente. Porque, assim... existe aqui uma reunião de conselho de saúde, a comunidade não participa [...]. Poucas pessoas vão" (M1E2ACS).

Com relação à situação de saúde, houve melhor discriminação, principalmente relacionada a fases do ciclo de vida como crianças e idosos, ou tipos de agravos (predominando a referência a situações crônicas como hipertensão e diabetes). Também foram feitas associações comuns, como por exemplo, entre pobreza e muitas crianças, entre idosos e doenças crônicas e acamados: "[...] Tem um número grande de hipertensos, porque eu pego uma área que tem bastante idoso, então tem um número grande de hipertensos, mas que estão bem controlados, [...]." (M1E3E).

Tais descrições das realidades eram, no geral, oriundas da percepção empírica do dia a dia do cuidado e de uma análise realizada a partir dela, sem referência a dados registrados ou a trabalho sistematizado de análise da realidade social. Isso é importante e pode ser considerado a partir de dois ângulos distintos: 1) como denotando fragilidade, superficialidade e ou ausência de construção tanto coletiva quanto individual de uma análise mais consistente dessa realidade sócio- político-sanitária; ou, por outro lado, e complementarmente, 2) como potencial matéria prima valiosa, fruto da elaboração individual e empírica do contato com a realidade local, a ser valorizada em espaços coletivos de gestão e organização (e educação permanente) do trabalho, como propõe $\mathrm{Campos}^{6}$, no sentido da ampliação do cuidado e da possível e potencial tematização de questões sociais e políticas de determinação social do processo saúde-doença-atenção.

Em relação aos dados levantados, rotineiramente, de forma estruturada sobre a realidade sociossanitária, os profissionais investigados foram unânimes em mencionar que as informações levantadas e registradas eram os dados dos cadastros das famílias (CAD-Família) e os dados de produtividade dos ACS (SIAB), estes regularmente registrados e enviados aos níveis centrais locais, estaduais e federais. Merece ser enfatizado e analisado a esse respeito que: 1) Os dados eram registrados e não eram sistematicamente analisados coletivamente, a não ser em algumas equipes pelos ACS em reuniões com suas enfermeiras, e em algumas poucas equipes em reuniões gerais, o que, contudo, pouco tem subsidiado de forma efetiva a proposição de ações de promoção, prevenção ou educação, segundo os entrevistados. 2) As análises, quando feitas (raramente) pelas equipes de saúde da família se referiam às doenças ou indicadores pré-definidos pelo município, e uma minoria das respostas mostrava haver algum balizamento do trabalho da equipe em torno destes marcadores. 3) Raramente havia algum uso destes registros, ocorrendo apenas quando de alguma demanda específica, geralmente assistencial, que gerava consulta a esses cadastros, a partir da necessidade de cuidado e intervenção.

Assim, esses registros têm servido mais para o cumprimento de obrigações burocráticas do que para uso da equipe para análise da realidade da comunidade e para planejamento de seu trabalho: "Não, a ficha A serve mais pra arquivo..." (M3E1ACS). "O dado ele é um... ele fica só uma informação sem muito significado, fica só uma coisa de preencher" (M1E2M). Isso pode ser uma situação geral no país, mas precisa ser confirmada com outras pesquisas sobre outros locais e regiões. Freitas e Pinto ${ }^{30}$ encontraram situação semelhante em Ribeirão Preto.

Ainda, em relação à análise realizada pelos profissionais, verificou-se que ela, na ampla maioria das vezes, era informal e realizada apenas quando necessário, ou seja, feita caso a caso, baseada no conhecimento da equipe sobre as realidades 
das famílias e usuários - um conhecimento que não se deve desprezar ou subestimar - quando das necessidades de atendimentos, de visitas domiciliares e de resoluções de casos complexos e ou graves de algum ponto de vista (clínico, psicológico, social, cultural): "É, a gente ta tentando trabalhar aí. Não é tão trabalhado. A gente passa mais sobre os problemas mais críticos, por exemplo, de paciente que ta com uma diabetes alta, descompensada, que a gente... aí traz pra equipe... e cada profissional que encontra alguma irregularidade, traz pra reunião de área e a gente tenta ver... resolver em conjunto" (M1E2E).

A prática de análise e reflexão sobre essas realidades restringia-se aos contextos familiares e microssocioculturais dos usuários, individualmente. Ocorria diluída no dia a dia da atenção à saúde e, ocasionalmente, nas reuniões periódicas das equipes de saúde da família, embora estas tenham sido referidas como pouco exploradas pela maior parte dos entrevistados que a elas fizeram menção. Isso mostra algo importante para a ESF, ainda que tangencial em relação aos objetivos da pesquisa: há alguma ampliação e interdisciplinaridade no cuidado, com avaliação de riscos, produção de projetos terapêuticos e hierarquização de prioridades, ao menos no cuidado clínico, com um tanto de longitudinalidade por parte da equipe, apesar das dificuldades e precariedades da ESF (rotatividade dos profissionais, vínculos precários e limitados, etc.).

\section{Proposição de ações, demandas e fluxos}

Como já mencionado, um dos achados importantes foi que o registro de dados sociosanitários (CAD-Família) e de envio de estatísticas de produtividade (SIAB) pouco ou nada influenciava ou contribuía para a geração de ações de promoção. Algumas vezes isso sofria algum grau de análise nas próprias equipes, mas as ações daí resultantes eram de cunho preventivista e individual, expressas em ações individuais e grupais.

Quando havia retorno ou comunicação do nível central, no geral, era para cobrar produtividade, não ocorrendo ações de promoção da saúde a partir destes dados: “[...] a gente só sabe que vai pra lá o documento e quando tem algum indicador desses aí que não está bem, aí sim [...]'Oh! a vacinação não deu a média', aí sim... 'hipertensos, tantos não estavam, não está atingindo a média”" (M1E1D); “A gente foi chamado na reunião porque o número do nosso preventivo tava baixo, fomos chamados pra saber, e foi através desse levantamento" (M1E3E).
A geração de demandas para outras secretarias ou serviços da própria Secretaria de Saúde implicando atividades intersetoriais ou interdisciplinares - necessárias para prevenção, terapêutica e promoção da saúde, praticamente não se dava a partir de atividades específicas de análise de realidade social (ditas, por vezes, de territorialização), nem a partir de dados registrados em planilhas (CAD-Família e SIAB). Nascia a partir de demandas de cuidado presentes na atividade assistencial individual e familiar, temperadas pela análise dos profissionais que têm um grau de conhecimento das condições de vida dos seus usuários, devido a sua imersão nas microáreas, notadamente os agentes de saúde. Assim, eram resultados de necessidades sentidas pelos profissionais a partir de casos individuais ou familiares (de natureza social, sanitária ou epidemiológica) que requeriam ações que transcendiam a APS centrada no cuidado médico/enfermagem. A partir destas demandas havia a geração de parcerias e realização de projetos pontuais, mais terapêuticos e preventivos: "Por exemplo, o agente de saúde traz um dado que tem uma casa que a pessoa tem muitos cachorros e ta com problemas com a higiene, problemas com vetores... o que a gente faz, neste caso, por exemplo, é entrar em contato com o controle de zoonose... A pessoa traz que tem casos de tuberculose em tal local, então, através disso, a gente vai fazer a visita, vai estar levando informações do controle da tuberculose no domicílio, tal, e vamos estar investigando os contatantes. Então tem tido esse fluxo sim, o agente de saúde traz na nossa reunião o... traz os dados, a gente vê juntos, daí pra ter uma ação" (M1E3M).

Ações propriamente de promoção da saúde, num sentido pós-carta de Ottawa, eram pouco realizadas, restringindo-se, salvo exceções, ao que se pode considerar de promoção de saúde envolvida nas atividades educativas e preventivas que várias das equipes investigadas realizavam.

Uma síntese geral e esquemática desses resultados encontra-se na Figura 2.

\section{Considerações finais}

A educação permanente e a promoção da saúde eram, em grande medida, desconhecidas e ausentes do pensamento e do trabalho dos profissionais investigados, com poucas exceções. Todavia, a maior parte dos profissionais estava mergulhada no labor do cuidado aos usuários: os ACS faziam sua rotina de vistas domiciliares 


\begin{tabular}{|c|l|}
\hline \multicolumn{2}{|c|}{ SÍNTESE DOS RESULTADOS E FLUXOS } \\
\hline $\begin{array}{c}\text { Concepção de } \\
\text { promoção de } \\
\text { saúde }\end{array}$ & $\begin{array}{l}\text { Promoção de saúde = prevenção de doenças } \\
\text { Realizada em atividades de educação individual e orientação, estas de caráter } \\
\text { eminentemente de transmissão de informações (educação bancária), feita em grupos ou } \\
\text { individualmente, em vários locais. Raras mençóes à promoção como qualidade de vida } \\
\text { dependente de condições sociais, econômicas e políticas, realizada em atividades de } \\
\text { caráter pedagógico participativo, associativo, político, dirigida à abordagem de } \\
\text { determinantes sociais e políticos do processo saúde-doença através de empowerment } \\
\text { comunitário, parcerias intersetoriais e estímulo à cidadania, democracia e } \\
\text { corresponsabilização por ações e condições de caráter coletivo. }\end{array}$ \\
\hline $\begin{array}{c}\text { Concepção de } \\
\text { educação } \\
\text { permanente }\end{array}$ & $\begin{array}{l}\text { Educação permanente = educação continuada } \\
\text { Realizada em atualizações científicas (nível superior) e capacitações para o trabalho, } \\
\text { necessárias para a correta transmissão das orientações e dos conhecimentos necessários } \\
\text { para a educação e a prevenção em saúde (identificada com promoção). }\end{array}$ \\
\hline $\begin{array}{c}\text { Análise da } \\
\text { realidade } \\
\text { social e de } \\
\text { saúde }\end{array}$ & $\begin{array}{l}\text { Análise intuitiva informal a partir do contato com a realidade social no dia a dia do } \\
\text { trabalho, realizada caso a caso e ou conforme demandas de cuidado e ações específicas, } \\
\text { ou por iniciativas individuais, discutidas de forma não organizada nem sistemática ou } \\
\text { registrada, em reuniões entre enfermeira e ACSs ou reuniões de equipe (mais } \\
\text { direcionada para as questões de saúde e ciclo de vida). Algum uso dos indicadores do } \\
\text { SIAB para avaliação de metas pré-definidas. }\end{array}$ \\
\hline
\end{tabular}

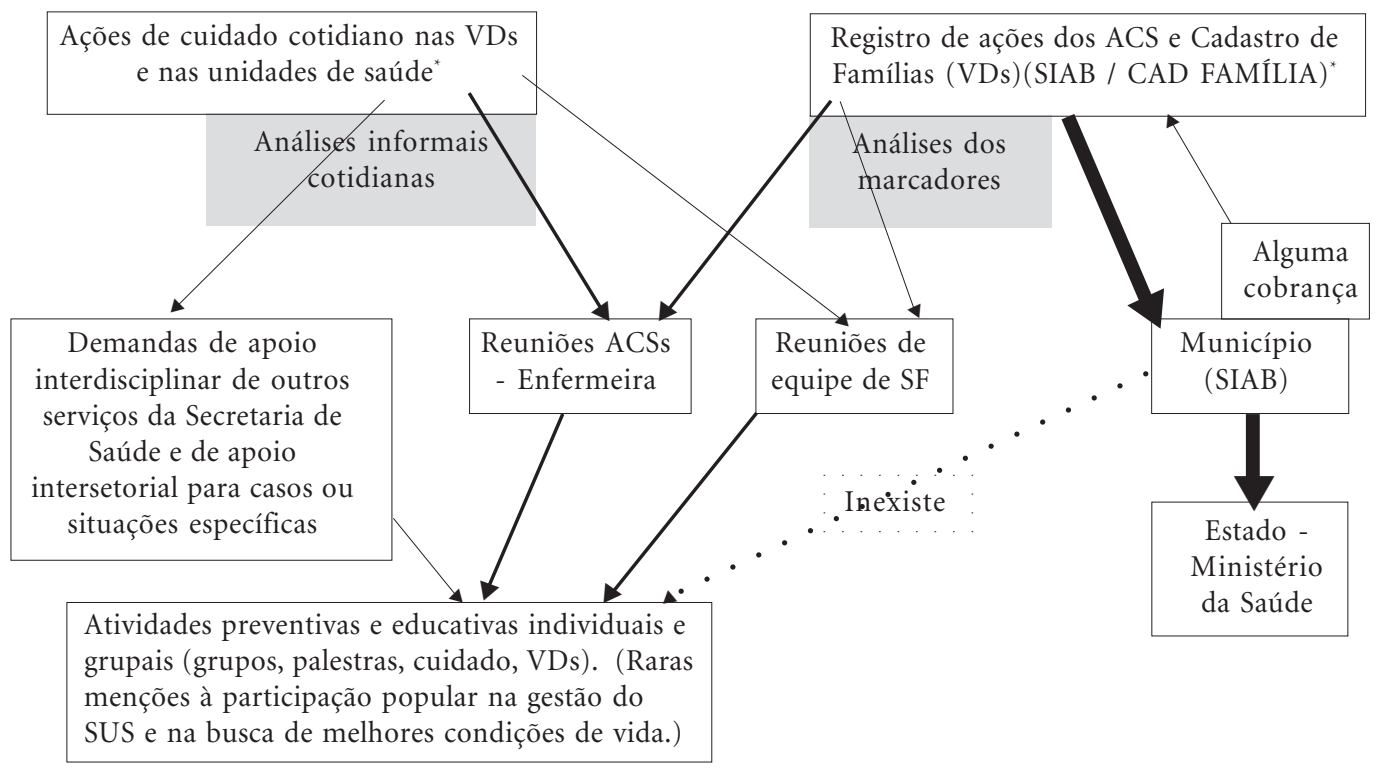

* A espessura das setas cheias refere-se à intensidade aproximada dos fluxos.

Figura 2. Diagrama sintético dos resultados

para alimentar o SIAB, reuniam-se com as enfermeiras mais assiduamente do que a equipe toda para discussão, análise e elaboração de projetos terapêuticos, ações educativas e preventi- vas. Além disso, as demandas por cuidado apontavam, algumas vezes, para recursos e ações que transcendiam as tecnologias biomédicas típicas da APS, exigindo parcerias e recursos de outros 
serviços e outros profissionais, quando então, ocorria construção de apoio e atividades pontuais em parceria.

Em que pese haver um quase sistemático alheamento da maioria dos profissionais para com as questões da promoção da saúde em seu sentido coletivo e social, eles estavam muito próximos do "espírito" educativo e preventivo, ainda que com uma visão educativa centrada em transmissão de conhecimentos e uma confusão entre promoção e prevenção que reduz os desafios, as missões e as propostas da promoção da saúde na ESF.

Pode-se concluir que os rituais e as atividades existentes de coleta sistemática de dados pouco alimentavam processos analíticos e de proposições de ações locais de promoção (conforme sua visão), mas os processos de trabalhos centrados na assistência aos usuários, por vezes, o faziam. Desse achado e de sua convergência com o ideário da educação permanente vem uma contribuição desta pesquisa: há necessidade de estímulo e de apoio institucional para que os profissionais de saúde possam ressignificar seus processos de leitura e de análise da realidade, no sentido de revalorizar a potencialidade que o próprio trabalho e a imersão na realidade dos usuários têm de gerar propostas de ações de promoção da saúde, bem como de terapêutica e prevenção.

É claro que o contato com o ideário da promoção da saúde contribui para a ampliação das perspectivas, mas esse contato e a crítica à educação como lógica de transmissão de conhecimento devem ser facilitados por arranjos institucionais de trabalho e apoio a ele, movimentos institucionais e de capacitação promovidos pelos níveis municipais ou loco-regionais. Neste caso, certamente, serão mais efetivos se chegarem capilarmente aos processos de trabalho das equipes e as apoiarem no manejo, interpretação, problematização e intervenção na realidade a partir dos casos e situações problemáticas detectadas.

Por outro lado, há que considerar que a efetividade e o impacto tanto de medidas preventivas, como demonstrou Rose ${ }^{31}$, quanto promotoras de saúde é maior quando aplicadas em abordagem populacional do que quando voltadas para intervenções individuais, mesmo que em grupos de maior risco, como hipertensos e diabéticos, os quais consomem significativa parte do tempo de trabalho dos ACS e das agendas de médicos e enfermeiros das equipes de saúde da família. De fato, na produção da saúde os sistemas de saúde têm um campo específico, muito valioso, porém limitado, já que se promove e "produz" mais saúde a partir de outros seto- res da sociedade $e^{9,32}$. Isso faz com que a responsabilidade por políticas e ações de promoção de saúde e prevenção de doenças recaia mais sobre os gestores locais (dos serviços), municipais, estaduais e federais, do setor saúde e de fora dele.

Assim, das equipes de saúde da família devese esperar o cuidado longitudinal e acessível e a coordenação desse cuidado para a coorte de usuários adscritos, que deve envolver criteriosas ações de prevenção e promoção nas dimensões individual, grupal e comunitária. Estas últimas são suscitadas mais facilmente quanto mais umbilicalmente estiverem ligadas à missão e à tarefa do cuidado, vocação fundamental da atenção primária e do setor saúde, que suscita mais "facilmente" ações preventivas e (potencialmente) promocionais, como os resultados apontam.

Nesse sentido, a educação permanente e sua assunção pelos gestores locais constituem-se em instrumento privilegiado de ampliação da qualidade da análise da realidade e da construção de ações de promoção da saúde e de cuidado, num contexto de democratização da gestão e das relações de trabalho. Ela poderá contribuir para a melhor compreensão da promoção da saúde e a superação da visão hierárquica e autoritária dos processos de educação e de trabalho, promovendo um pouco de "empowerment" comunitário nos profissionais e, assim, facilitar o nascimento da compreensão (e ação) do que seja isso em relação aos usuários.

\section{Colaboradores}

CD Tesser, AV Garcia, C Vendruscolo e CE Argenta participaram de todas as fases da pesquisa e da elaboração do artigo.

\section{Agradecimentos}

Agradecemos aos profissionais participantes da pesquisa e ao $\mathrm{CNPq}$ por financiá-la. 


\section{Referências}

1. Starfield B. Atenção Primária: equilíbrio entre necessidades de saúde, serviços e tecnologia. Brasília: Unesco, Ministério da Saúde (MS); 2002.

2. Brasil. Ministério da Saúde. Política Nacional de Atenção Básica 2006. [acessado 2009 mai 20]. Disponível em: http://bvsms.saude.gov.br/bvs/publicacoes/ politica_nacional_atencao_basica_2006.pdf

3. Peduzzi M. Atividades educativas de trabalhadores na atenção primária: concepções de educação permanente e de educação continuada em saúde presentes no cotidiano de Unidades Básicas de Saúde em São Paulo. Interface - Comun Saude Educ 2009; 13(30):121-134.

4. Ceccim RB. Educação Permanente em Saúde: descentralização e disseminação da capacidade pedagógica na saúde. Cien Saude Colet 2005; 10(4):975986.

5. Ceccim RB, Feuerwerker LCM. O quadrilátero da formação para a área da saúde: ensino, gestão, atenção e controle social. Physis Rev Saúde Coletiva 2004; 14(1):41-65.

6. Campos GWS. Um método para análise e co-gestão de coletivos: a constituição do sujeito, a produção de valor de uso e a democracia em instituições: o método da roda. São Paulo: Hucitec; 2000.

7. Carvalho SR. Os múltiplos sentidos da categoria "empowerment" no projeto de Promoção à Saúde. Cad Saude Publica 2004; 20(4):1088-1095.

8. Czeresnia D, Freitas CM, organizadores. Promoção da saúde: conceitos, reflexões, tendências. Rio de Janeiro: Ed. Fiocruz; 2003.

9. Sícoli JL; Nascimento PR. Promoção de saúde: concepções, princípios e operacionalizações. Interface - Comunic. Saude Educ. 2003; 7(12):101-122.

10. Westphal MF. Promoção da saúde e prevenção de doenças. In: Campos GWS, Minayo MCS, Akerman M, Drumond Jr M, Carvalho YM, organizadores. Tratado de saúde coletiva. São Paulo: Hucitec Rio de Janeiro: Ed. Fiocruz; 2006. p. 635-668.

11. Carvalho SR. Saúde Coletiva e promoção da saúde: sujeito e mudança. São Paulo: Hucitec; 2005.

12. Lefevre F, Lefevre AMC. Promoção de saúde: a negação da negação. Rio de Janeiro: Vieira \& Lent; 2004.

13. Castiel LD, Diaz CAD. A saúde persecutória: os limites da responsabilidade. Rio de Janeiro: Ed. Fiocruz; 2007.

14. Tesser CD, organizador. Medicalização social e atenção à saúde no SUS. São Paulo: Hucitec; 2010.

15. Nogueira RP. A saúde pelo Avesso. Natal: Seminare Editora; 2003.

16. Bardin L. Análise de conteúdo. $3^{\mathrm{a}}$ ed. Lisboa: Edições 70; 2004

17. Martins J, Bicudo MAA. Pesquisa qualitativa em Psicologia. São Paulo: Ed. Moraes; 1994.

18. Leavell H, Clark EG. Medicina preventiva. São Paulo: McGraw Hill do Brasil; 1976.
19. Mascarenhas CV. Promoção da saúde: representações sociais de acadêmicos dos cursos de graduação na área da saúde [dissertação]. Florianópolis (SC): Universidade Federal de Santa Catarina; 2005.

20. Cervera DPP, Goulart B. Educação em saúde: percepção dos enfermeiros da atenção básica, em Uberaba-MG. Cien Saude Colet [periódico na Internet]. 2009 [acessado 2009 mai 20];16(Supl. 1):1547-1554. Disponível em: http://www.abrasco. org.br/cienciaesaudecoletiva/artigos/artigo_int.php ?id_artigo $=3173$

21. Freire P. Educação e Mudança. 23a ed. Rio de Janeiro: Paz e Terra; 1999.

22. Freire P. Pedagogia da autonomia. Saberes necessários à prática educativa. 13 a ed. Rio de Janeiro: Paz e Terra; 1987

23. Conill EM. Ensaio histórico-conceitual sobre a Atenção Primária à Saúde: desafios para a organização de serviços básicos e da Estratégia Saúde da Família em centros urbanos no Brasil. Cad Saude Publica 2008; 24 (Supl. 1):s7-s16.

24. Conill EM. Políticas de atenção primária e reformas sanitárias: discutindo a avaliação a partir da análise do Programa Saúde da Família em Florianópolis, Santa Catarina, Brasil, 1994-2000. Cad Saude Publica 2002; 18(Supl. 1):191-202.

25. Pessanha RV, Cunha FTS. A aprendizagem-trabalho e as tecnologias de saúde na Estratégia Saúde da Família. Texto \& Contexto Enfermagem [periódico na Internet]. 2009 [acessado 2009 set 22];18(2): 233-240. Disponível em: http://www.scielo.br/pdf/ tce/v18n2/05.pdf

26. Cyrino AP, Schraiber LB. Promoção da saúde e prevenção de doenças: o papel da educação e da comunicação. In: Martins MA, Carrilho FJ, Alves VAF, Castilho EA, Cerri GG, Wen CL, organizadores. Clínica Médica. Barueri: Manole; 2009. v. 3. p. 470-477.

27. Bourdieu P. Esboço de uma teoria prática. In: Ortiz R, organizador. Sociologia. Rio de Janeiro: Ática; 1983. p. 46-81.

28. Rosen G. Da polícia médica à medicina social: ensaios sobre a história da assistência médica. Rio de Janeiro: Edições Graal; 1979.

29. Campos CEA. As origens da rede de serviços de atenção básica no Brasil: o Sistema Distrital de Administração Sanitária. Hist. cienc. saúde - Manguinhos 2007; 14(3):877-906.

30. Freitas FP, Pinto IC. Percepção da equipe de saúde da família sobre a utilização do sistema de informação da atenção básica - SIAB. Rev. Latino-Am. Enfermagem 2005; 13(4):547-554.

31. Rose G. Estratégias da medicina preventiva. Porto Alegre: Artmed; 2010.

32. Mckeown T. El papel de la medicina: sueño, espejismo o némesis? México D.F.: Siglo veintiuno editores; 1982 